\title{
33. A PALEOMAGNETIC STRATIGRAPHY FOR OLIGOCENE AND EARLY MIOCENE MARINE GLACIAL SEDIMENTS AT SITE 270, ROSS SEA, ANTARCTICA
}

\author{
Richard G. Allis, ${ }^{1}$ Peter J. Barrett, David A. Christoffel, Victoria University of Wellington, New Zealand
}

\begin{abstract}
A paleomagnetic study has been carried out on a sequence of Oligocene and early Miocene marine glacial sediments recovered from DSDP Site 270 in the Ross Sea, Antarctica. The reversal stratigraphy for 30 to 240 meters below bottom compares closely with the early Miocene part of the sea-floor anomaly scale of Heirtzler et al. (1968). The linear relationship not only requires a constant sedimentation rate of $41 \mathrm{~m} / \mathrm{m} . \mathrm{y}$., but at the same time confirms the regularity of polarity change for this part of the Heirtzler et al. scale. The interval from 240 to 370 meters below bottom is entirely normally magnetized, possibly because of a change in the magnetic character of the sediments due to the formation of magnetically unstable authigenic minerals. The sedimentation rate probably remained almost constant, because the same sedimentary facies occur throughout the glacial marine sequence, and because the three reversals from 370 to 384 meters, the base of the glacial sequence, indicate a sedimentation rate similar to that for the upper part.

Comparison with the Heirtzler et al. scale and extrapolation of the sedimentation rate into the long 'normal' interval places the Oligocene-Miocene boundary ( 22.5 m.y.) at 260 meters below bottom, compared with about 300 meters below bottom for the boundary based on benthonic foraminifera. The base of the glacial sequence is believed to be 25 m.y.
\end{abstract}

\section{INTRODUCTION}

Site 270 (Figures 1, 2) penetrated 20 meters of soft Plio-Pleistocene glacial mud (Unit 1), which was not sampled because of the degree of core deformation. This layer rests with slight angular unconformity $\left(1^{\circ}-2^{\circ}\right)$ on a 364-meter-thick semi-lithified to lithified marine glacial sequence (Unit 2) which was the object of this investigation. Unit 2 is underlain disconformably by a thin preglacial sequence (Units 3, 4, and 5). A basement of calc-silicate gneiss was encountered at 412 meters below bottom.

The sediments of Unit 2 are silty claystones and clayey siltstones with sparsely scattered sand, granules, and pebbles, and have been divided into 3 lithofacies and 10 subunits on the basis of subtle differences in bedding character and clast distribution (see Chapter 8, this volume).

Age determinations based on sparse benthonic foraminifera indicate an age no older than Oligocene for the lower part of Unit 2, and place the OligoceneMiocene boundary 280 meters below the top (300 m below bottom). Faunas are too poor for ages to be assigned to the upper part of Unit 2 (see Chapter 8, this volume).

\footnotetext{
'Now at Department of Physics, University of Toronto, Toronto, Canada.
}

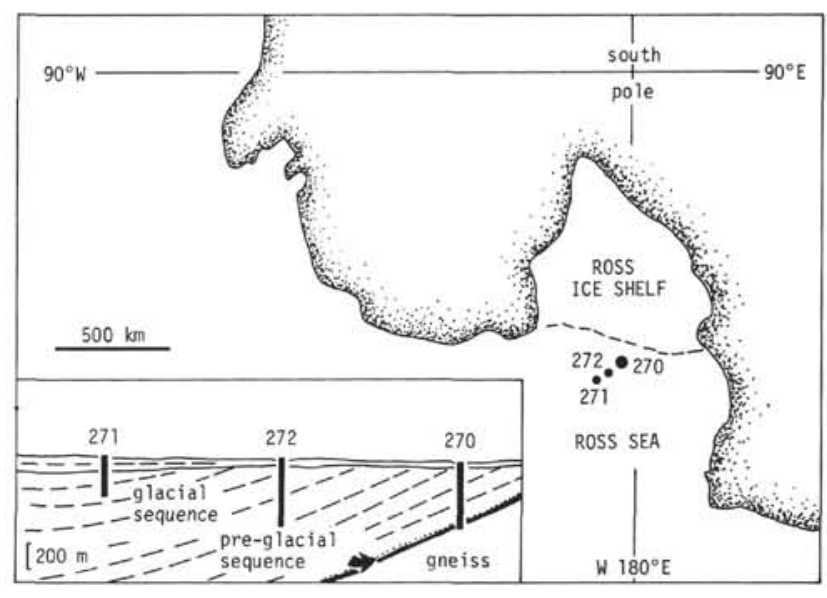

Figure 1. Locality map and cross-section for drill sites in the south central Ross Sea.

\section{SAMPLING, PREPARATION, AND MEASUREMENT}

Core samples were taken on the ship, and were oriented with an arrow indicating the up-hole direction. No azimuthal orientation was possible because of the rotation of core segments (normally $5-20 \mathrm{~cm}$ long) during drilling. Specimens $3-6 \mathrm{~cm}^{3}$ in volume were cut from selected samples. Magnetic intensity and inclination were measured on a $5-\mathrm{Hz}$ spinner magnetometer, similar to the design of Foster (1966). Measurements were made 


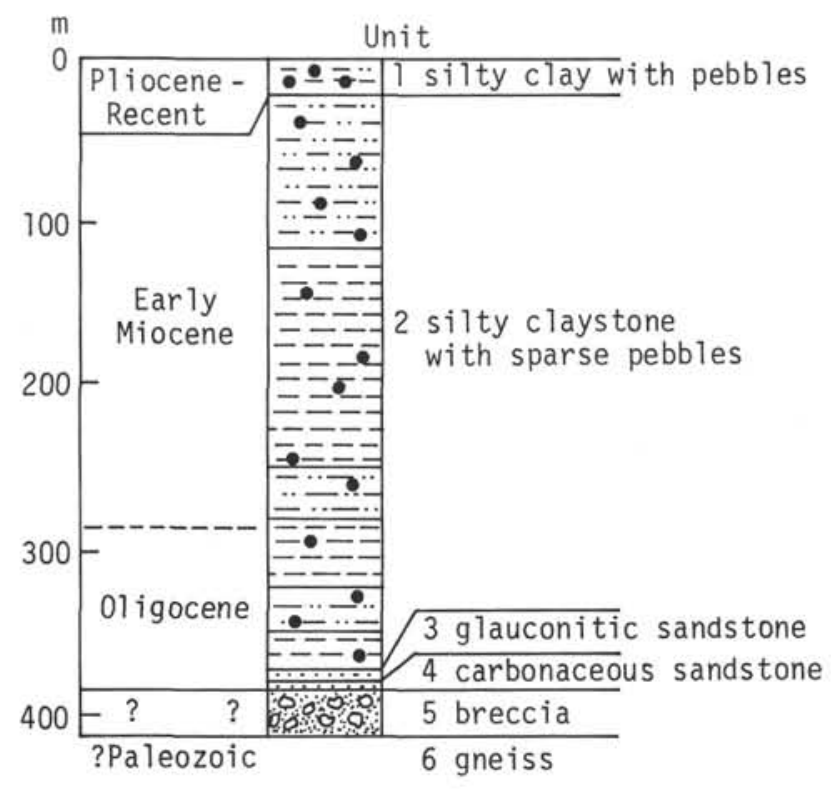

Figure 2. Stratigraphic column for Site 270, Ross Sea.

of both natural remanent magnetization (NRM) and partial thermal remanent magnetization (PTRM) after thermal demagnetization (see below). Specimens were weighed after the cleaning process, and the intensities of magnetization have been expressed in emu/g.

A preliminary study to determine the paleomagnetic properties of the sediment was made on 50 specimens. Most of these were spaced at about 10-meter intervals in the upper part of the unit, and revealed a pattern of normal and reversed NRM. From the frequency of polarity changes with depth, the sedimentation rate was estimated to be of the order of $50 \mathrm{~m} / \mathrm{m}$.y. It was therefore decided to obtain measurements from at least one point for every 5 meters of core length, so that no magnetic events of more than 100,000 years would be missed. Over much of the upper 80 meters of the unit, core recovery is less than $50 \%$, and this has left unsampled six intervals of between 5 and 7 meters each representing not more than 140,000 years. Where changes in polarity were indicated by only one or two specimens, further specimens were cut from adjacent samples to determine whether the polarity change resulted from a significant geomagnetic event or from local core disturbance.

More than one specimen was cut from the horizon for seven samples to check the consistency of the measurements. The results (Table 1) indicate that, for most specimens, magnetic intensities are within about $10 \%$ and inclinations within $10^{\circ}$. However, these values increase for specimens with intensities of magnetization less than about $3 \times 10^{-6} \mathrm{emu} / \mathrm{g}$, as the maximum sensitivity of the magnetometer is approached. About $15 \%$ of the specimens are in this category.

\section{STABILITY OF MAGNETIZATION}

Initially progressive thermal demagnetization was carried out on nine specimens, by raising the cleaning temperature in $50^{\circ} \mathrm{C}$ steps to $300^{\circ} \mathrm{C}$, and measuring the PTRM after each step (Figure 3). The shapes of the cleaning curves and the reversal pattern in the NRM in the upper part of the unit (30-240 m below bottom) indicate that the magnetization of the sediments in this interval is partially stable, similar to that of many deep-sea sediments (Opdyke et al., 1966). All samples were

TABLE 1

Intensity and Inclination Measured After Thermal Demagnetization

\begin{tabular}{|c|c|c|c|c|c|}
\hline $\begin{array}{c}\text { Sample } \\
\text { (Interval in } \mathrm{cm} \text { ) }\end{array}$ & $\begin{array}{l}\text { Depth Below } \\
\text { Bottom } \\
\text { (m) }\end{array}$ & $\begin{array}{c}\text { Intensity } \\
(\mathrm{emu} / \mathrm{g} \\
\left.\times 10^{-6}\right)\end{array}$ & $\begin{array}{l}\text { Inclination } \\
\text { (deg) }\end{array}$ & $\begin{array}{c}\text { Difference } \\
\text { in Intensity } \\
(\%)\end{array}$ & $\begin{array}{l}\text { Difference in } \\
\text { Inclination } \\
\text { (deg) }\end{array}$ \\
\hline \multicolumn{6}{|l|}{$\mathbf{A}^{\mathrm{a}}$} \\
\hline $6-2,36-42$ & 35 & $\begin{array}{l}4.4 \\
5.0\end{array}$ & $\begin{array}{l}-50 \\
-55\end{array}$ & 13 & 5 \\
\hline $17-2,83-88$ & 140 & $\begin{array}{l}7.5 \\
7.4\end{array}$ & $\begin{array}{l}-17 \\
-27\end{array}$ & 1 & 10 \\
\hline $18-2,138-140$ & 150 & $\begin{array}{l}13.9 \\
14.4\end{array}$ & $\begin{array}{l}+78 \\
+76\end{array}$ & 4 & 2 \\
\hline $\begin{array}{l}18-4,77-80 \\
\text { B }^{\text {b }}\end{array}$ & 153 & $\begin{array}{l}27.9 \\
26.0\end{array}$ & $\begin{array}{l}+60 \\
+68\end{array}$ & 7 & 8 \\
\hline $24-1,42-47$ & 206 & $\begin{array}{l}2.4 \\
2.9\end{array}$ & $\begin{array}{l}+55 \\
+13\end{array}$ & 19 & 42 \\
\hline $27-4,140-145$ & 239 & $\begin{array}{l}1.1 \\
2.4\end{array}$ & $\begin{array}{c}0 \\
-70\end{array}$ & 104 & 70 \\
\hline $42-4,150-160$ & 374 & $\begin{array}{l}2.1 \\
1.1 \\
1.0 \\
2.0 \\
2.3 \\
1.9\end{array}$ & $\begin{array}{l}-63 \\
-14 \\
-16 \\
-68 \\
-44 \\
-36\end{array}$ & 76 & 54 \\
\hline
\end{tabular}

${ }^{\mathrm{a}}$ Pairs of specimens from typical samples at $150^{\circ} \mathrm{C}$.

${ }^{\mathrm{b}}$ Multiple specimens from samples with low magnetizations (15\% of total) 

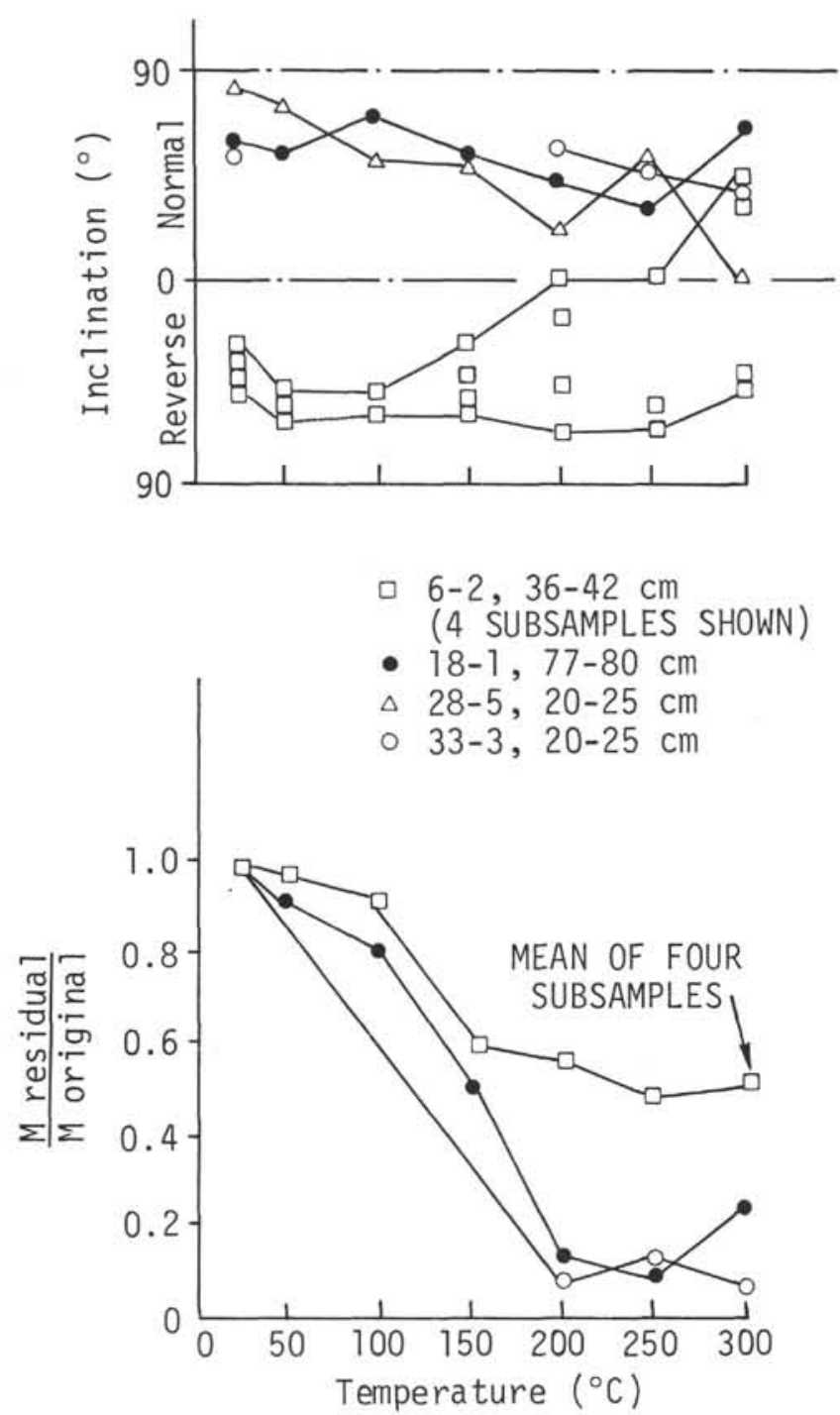

Figure 3. A plot of changes in magnetic intensity during progressive thermal demagnetization of typical specimens from Site 270.

therefore cleaned at $150^{\circ} \mathrm{C}$. This appears to have been sufficient to remove low temperature viscous components; 66 specimens out of 72 showed only small changes in inclination, although 6 changed polarity from normal to reversed.

In the interval from 240 to 370 meters below bottom the NRM remains normal and has a relatively high intensity. Thermal demagnetization of three specimens at temperatures up to $300^{\circ} \mathrm{C}$ showed magnetic behavior similar to that of specimens higher in the unit (Figure 2). Cleaning of 20 specimens from this interval at $400^{\circ} \mathrm{C}$ and $450^{\circ} \mathrm{C}$ did result in some reversals of magnetization with low inclinations at both temperatures. Consistency between the sets of measurements on these latter specimens is poor (Figure 4). Possibly a more refined demagnetization method can isolate a primary remanent magnetization.
For the interval from 370 meters to the base of the unit ( $384 \mathrm{~m}$ below bottom) the magnetic behavior of the specimens is very similar to that in the upper part of the unit, apart from a lower intensity.

\section{RESULTS}

The reversal stratigraphy from the top of Unit 2 to 233 meters below bottom (Figure 5) compares very closely with the geomagnetic field reversal time scale based on sea-floor anomalies (Heirtzler et al., 1968) for the period from 17 to 22 m.y. (Figure 6). This implies not only a nearly constant sedimentation rate of $41 \pm 1$ $\mathrm{m} / \mathrm{m}$.y. for the 205 meters of sediment, but also the linearity of the Heirtzler et al. time scale for this interval. There is unlikely to be a causal connection between the sedimentation rate at Site 270 and spreading rate of the South Atlantic Ocean, on which the scale is based.

If the sedimentation rate is extrapolated a short distance below the lowest reversal control point at 233 meters below bottom, the Oligocene-Miocene boundary at 22.5 m.y. (Berggren, 1972) is at 260 meters. The foraminiferal evidence to date (see Chapter 8 , this volume) suggests that the boundary lies between 293 and 309 meters.

Just below 150 meters below bottom the presence of three reversed specimens and two with zero inclination indicates a previously undetected magnetic event lasting between 0.02 and 0.12 m.y., assuming the above sedimentation rate. The zero values for inclination may be explained by deposition close to a polarity change because of signs of burrowing in the two samples. However, they are 0.9 meters apart, representing a period of 0.02 m.y. With our preferred time scale, this additional reversal would occur in the interval between 19.82 and 19.84 m.y. One specimen at 200 meters may also indicate a short reversal at 21.08 m.y. but the large fluctuations in inclination at this depth make it doubtful. The fluctuations may result from penecontemporaneous disturbance indicated by the abundance of deformed claystone clasts in Cores 21 to 23 (Chapter 8, this volume).

A short-duration reversal of 0.03 m.y. at 17.80 m.y. in the Heirtzler et al. scale was not detected, but could easily have been missed as the sampling interval at the corresponding depth $(70-73 \mathrm{~m})$ represents about $0.1 \mathrm{~m} . \mathrm{y}$.

The mean inclination for the specimens 30-233 meters below bottom is $45^{\circ}$, with a standard deviation of $24^{\circ}$. This is significantly below the $85^{\circ}$ expected from the high latitude of the drill site during the Tertiary. No reason for this difference is known.

The long normally magnetized interval from 240 to 370 meters below bottom can be explained in three ways: (1) a sudden and dramatic change in the sedimentation rate (from roughly $500 \mathrm{~m} / \mathrm{m} . \mathrm{y}$. to $41 \mathrm{~m} / \mathrm{m}$.y. for the overlying sequence); 2) a change in the grain size or mineralogy of the detrital magnetic grains, due to a change in source; and 3) a change in the depositional or postdepositional environment, which had favored the formation of authigenic magnetic minerals.

This interval does include two short sections of 10 and 23 meters at 250 and 320 meters below bottom, respectively, where bedding dips at $20^{\circ}$ to $50^{\circ}$, indicating 

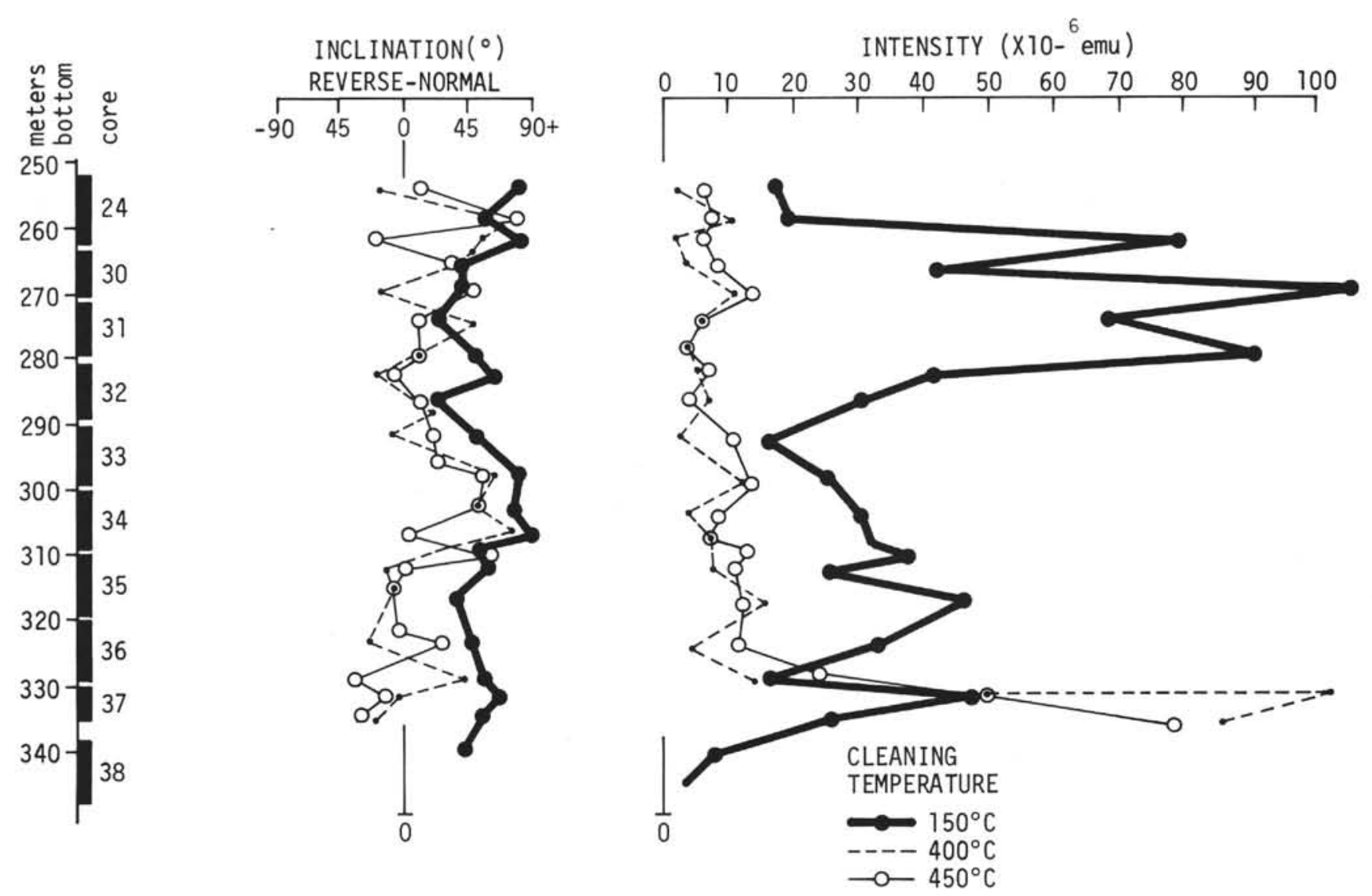

Figure 4. Plots of inclination and intensity with depth after thermal demagnetization at $150^{\circ} \mathrm{C}, 400^{\circ} \mathrm{C}$, and $450^{\circ} \mathrm{C}$, for the interval from 250 to 340 meters. The lack of consistency clearly indicates the low stability of the high temperature component of the magnetization.

slumping. However, the relatively high magnetic intensity over the interval compared with that above suggests a change in magnetic character of the sediments rather than a change in sedimentation rate. Both the abundances of various pebble lithologies and the proportions of pebbles and clay in the sediments (Barrett, this volume) show no obvious or consistent variations that could indicate a change in the sediment source or in the balance of the depositional processes. Furthermore, shore laboratory X-ray data (Cook et al., this volume) show no significant change in mineral composition that might be related to the loss of magnetic stratigraphy.

Our favored explanation at present is that the loss in magnetic stratigraphy results from the authigenic formation of a magnetic mineral-perhaps maghemite or pyrrhotite-with unstable magnetization. Shipboard records show six occurrences of brassy sulfide nodules, described as pyrite, between 215 and 355 meters but shore laboratory X-ray data record pyrite only from outside the long normal magnetic interval. A similar instability of magnetization, though on a much smaller time scale, has been observed in many red clays in the Pacific region, and has been related to an increase in the proportion of manganese micronodules (Haggerty, 1970). However, smear slide descriptions for Unit 2 at Site 270 indicate only trace amounts of micronodules, and analyses show that the glacial sediments at Site 270 have an unusually low manganese content (Frakes, Chapter 25, this volume).

The reversal stratigraphy reappears near the base of Unit 2 (370-384 m below bottom). Although the three polarity changes cannot be uniquely related to the Heirtzler et al. time scale, an approximate age for the base of the glacial sequence can be obtained by assuming a constant sedimentation rate for the interval. If a sedimentation rate similar to that higher in Unit 2 is assumed, either of the two bracketed lines A (Figure 6) fits the data best, and indicates an age of either 25 or 25.5 m.y. for the base of the unit. Alternative fits are possible if the sedimentation rate is reduced by a factor of 4 or if it is initially $20 \mathrm{~m} / \mathrm{m}$.y. and then rises to 100 $\mathrm{m} / \mathrm{m}$.y. before settling down to the well-established 41 $\mathrm{m} / \mathrm{m}$.y. for the upper 200 meters of the unit. The similar lithologic character throughout the unit supports the first interpretation.

\section{CONCLUSIONS}

1. A paleomagnetic chronology has been established for the interval 20 to 233 meters below bottom in DSDP Site 270 in the Ross Sea. The reversal stratigraphy closely matches the Heirtzler et al. (1968) scale for the period from 17 to 22 m.y. 


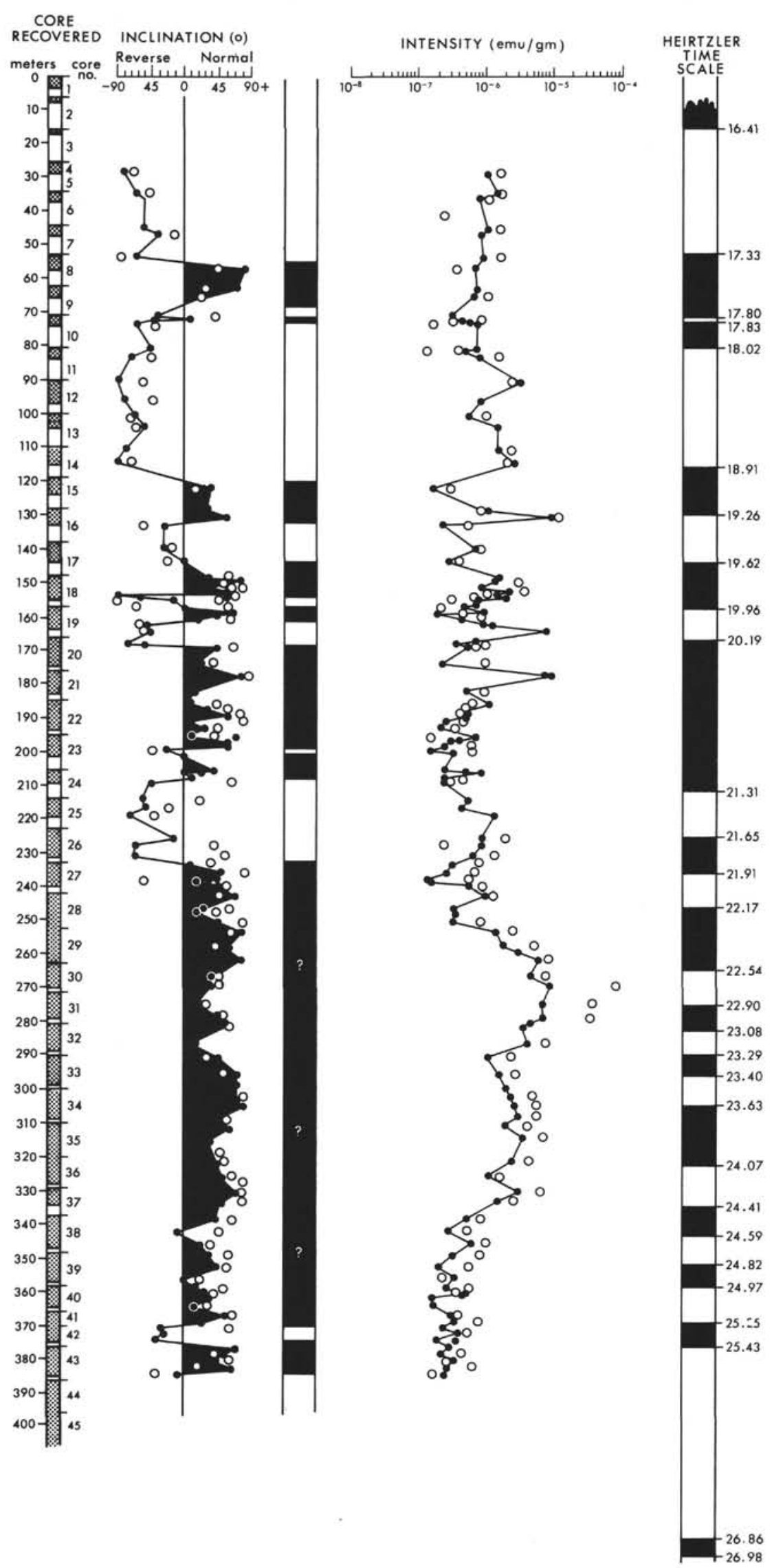

Figure 5. Plots of inclination and intensity with depth before cleaning (circles) and after cleaning at $150^{\circ} \mathrm{C}$ (dots) for Unit 2, Site 270 . The reversal stratigraphy for the upper part compares closely with the time scale of Heirtzler et al. (1968). 


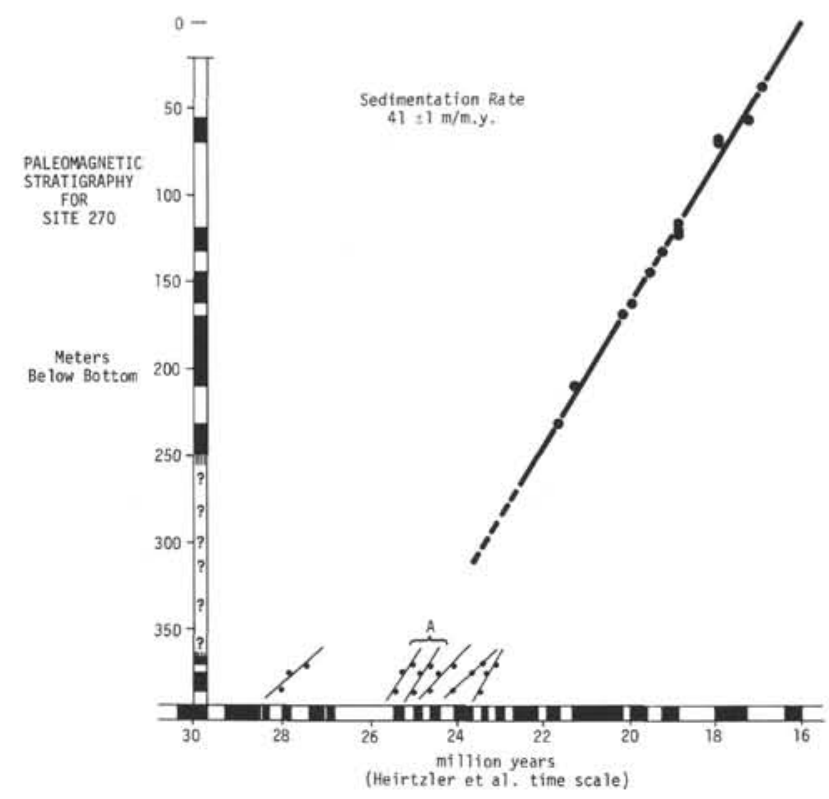

Figure 6. A plot of below bottom depth to each reversal in Site 270 against the time indicated by the Heirtzler et al. sea-floor anomaly time scale. The linearity of the regression line indicates a constant sedimentation rate of $41 \pm 1$ $\mathrm{m} / \mathrm{m} . \mathrm{y}$. The six lines near the base of the hole indicate the only six likely positions in time for the three polarity changes. The two marked $A$ are considered the most likely and give an age of 25 or 25.5 m.y. for the base of the glacial sequence.

2. An additional short reversal between 0.02 and 0.12 m.y. at 19.6 m.y. has been detected.

3. The sedimentation rate for the interval is $41 \pm 1$ $\mathrm{m} / \mathrm{m} . \mathrm{y}$, and was more or less constant for the period.
4. The long interval of normal magnetization from 230 to 370 meters below bottom is attributed to destruction of the detrital remanent magnetization by authigenic growth of minerals with unstable magnetization.

5. Using the sedimentation rate of $41 \mathrm{~m} / \mathrm{m} . \mathrm{y}$., the Oligocene-Miocene boundary is at 260 meters below bottom, in reasonable agreement with its location at 300 meters from foraminiferal evidence.

6. The age of the base of the glacial sequence is by extrapolation either 25 or 25.5 m.y.

\section{ACKNOWLEDGMENTS}

Financial support for laboratory work was provided by the Victoria University of Wellington's Internal Research Committee.

\section{REFERENCES}

Berggren, W. A., 1972. A Cenozoic time-scale-some implications for regional geology and paleobiogeography: Lethaia, v. 5, p. 195-215.

Foster, J. H., 1966. A paleomagnetic spinner magnetometer using a fluxgate gradiometer: Earth Planet. Sci. Lett., v. 1, p. $463-466$.

Haggerty, S. E., 1970. Magnetic minerals in pelagic sediments. Carnegie Inst. Wash. Year Book, v. 68, p. 332-336.

Heirtzler, J. R., Dickinson, G. O., Herron, E. M., Pitman, W. C., III, and Le Pichon, X., 1968. Marine magnetic anomalies, geomagnetic field reversals and motions of the ocean floor and continents: J. Geophys. Res. v. 73, p. 2119 2136.

Opdyke, N. D., Glass, B., Hays, J. D., and Foster, J., 1966. Paleomagnetic study of Antarctic deep-sea cores: Science, v. 154 , p. $349-357$. 